\title{
CURSOS DE LICENCIATURA E A PREPARAÇÃO PARA A ATUAÇÃO DOCENTE FUTURA: A PERCEPÇÃO DE FORMANDOS
}

\author{
Raquel Stoilov Pereira ${ }^{1}$ \\ Adriane Letícia Siqueira dos Santos ${ }^{2}$ \\ Marcos Aurélio de Souza Alves ${ }^{3}$ \\ Neiva Egídia da Silva Mello ${ }^{4}$
}

PEREIRA, R. S.; SANTOS, A. L. S. dos; ALVES, M. A. de S.; MELLO, N. E. da S. Cursos de licenciatura e a preparação para a atuação docente futura: a percepção de formandos. EDUCERE - Revista da Educação, Umuarama, v. 20, n. 1, p. 159-185, jan./jun. 2020.

RESUMO: Esta pesquisa teve por objetivo identificar a percepção dos alunos do penúltimo e último semestre de cursos de licenciatura, em relação à preparação para a atuação docente futura na educação básica. A pesquisa caracteriza-se como do tipo descritiva com abordagem qualitativa e ocorreu em uma Instituição de Ensino Superior localizada na região metropolitana de Cuiabá-MT, contando com a participação de 49 alunos, sendo 34 do curso de licenciatura em Educação Física, 10 do curso de Pedagogia e 5 do curso de Letras, com idade média de 30 anos. Como instrumento de pesquisa adotamos um questionário composto por 18 questões, sendo 03 abertas e 15 fechadas. Concluímos que apesar de dificuldades isoladas identificadas durante os estágios e práticas de ensino, o processo formativo contribuiu para preparação e atuação como docente, indicando que a instituição pesquisada caminha em uma direção positiva em relação à qualidade da formação desses futuros professores.

PALAVRAS-CHAVE: Alunos; Formação de Professores; Educação Bá-

DOI: 10.25110 /educere.v20i1.2020.7564

${ }^{1}$ Mestre em Educação Física, Doutoranda em Ciências, pela Escola de Educação Física e Esporte da Universidade Federal de São Paulo - EEFE-USP, docente do curso de Educação Física do Centro Universitário de Várzea Grande - UNIVAG. Email: raquelspmoreira@usp.br

${ }^{2}$ Licenciada em Educação Física pelo Centro Universitário de Várzea Grande - UNIVAG. Email: adrianeleticia15@gmail.com

${ }^{3}$ Licenciado em Educação Física pelo Centro Universitário de Várzea Grande - UNIVAG. Email: marcao_aurelliioo@hotmail.com

${ }^{4}$ Licenciada em Educação Física pelo Centro Universitário de Várzea Grande - UNIVAG. Email: neiva.egidia@gmail.com 
sica.

\title{
UNDERGRADUATE COURSES AND PREPARATION TO FUTURE TEACHING PRACTICE: THE PERCEPTION OF THE GRADUATING STUDENTS
}

\begin{abstract}
This research aims at identifying the perception of the students of the penultimate and last semester of the undergraduate course in relation to the preparation to future teaching practice in elementary education. The research is characterized as descriptive using a qualitative approach, and was developed in a Higher Education Institution in the metropolitan region of Cuiabá, in the state of Mato Grosso. A total of 49 students took part, with 34 from the Physical Education undergraduate course, 10 from the Pedagogy course and 5 from Linguistics course, with average age of 30 years old. A questionnaire with 18 questions was applied as the research instrument, consisting of 3 open-ended and 15 closedended questions. It can be concluded that even though isolated difficulties were identified during the internship and the teaching practices, the training process contributed to the preparation and practice as a teacher, indicating that the institution researched is positively classified in relation to the quality of training provided to future teachers.
\end{abstract}

KEYWORDS: Students; Teacher Training; Elementary Education.

\section{CURSOS DE LICENCIATURA Y LA PREPARACIÓN PARA LA ACTUACIÓN DOCENTE FUTURA: LA PERCEPCIÓN DE GRADUANDOS}

RESUMÉN: Esta pesquisa tuvo por objetivo identificar la percepción de estudiantes del penúltimo y último semestre de cursos de licenciatura, en relación a la preparación para la actuación docente futura en educación básica. La investigación se caracteriza como descriptiva con abordaje cualitativa y ocurrió en una Institución de Enseñanza Superior localizada en la región metropolitana de Cuiabá-MT, contando con la participación de 49 estudiantes, siendo 34 del curso de licenciatura en Educación Física, 10 del curso de Pedagogía y 5 del curso de Letras, con edad mediana de 30 años. Como instrumento de pesquisa adoptamos 
un cuestionario compuesto por 18 cuestiones, siendo 03 abiertas y 15 cerradas. Concluimos que, a pesar de dificultades aisladas identificadas durante las pasantías y prácticas de enseñanza, el proceso formativo contribuyó para la preparación y actuación como docente, indicando que la institución pesquisada camina en una dirección positiva en relación a la calidad de la formación de esos futuros profesores.

PALABRAS CLAVE: Estudiantes; Formación de Profesores; Educación Básica.

\section{INTRODUÇÃO}

De acordo com Saviani (2009), o cenário de discussão voltado à formação de professores é muito amplo, visto que passou a ser referência nas pesquisas a partir do século XIX, impulsionada pela Revolução Francesa que resultou na criação das Escolas Normais, responsáveis por preparar professores.

O autor afirma ainda que no Brasil os estudos sobre a formação de professores emergem após a independência, culminando na organização da instrução popular articulada às transformações que ocorriam nesse tempo. Em 1827, no país, a lei das escolas de primeiras letras, obriga a formar os professores num método mútuo, em que os docentes eram "treinados" às próprias custas,

[...] baseado no saber provindo da experiência, ou seja, por meio do contato com o trabalho de um professor já experiente e atuante, se aprenderia como ensinar. A observação do trabalho de um professor em sala de aula possibilitaria a vivência e os conhecimentos necessários para aprender a função de professor. Nesse sentido, aprender a ser professor estava relacionado com a observação, convivência e imitação. [...] Essa maneira, baseada na aprendizagem do método mútuo, [...] marcou a formação de professores no Brasil no século XIX. (GUEDES; SCHELBAUER, 2010, p. 229).

Deste modo, a formação de professores baseava-se na mera observação, utilizando um método que possibilitava somente ao aluno as- 
similar as ações de um professor experiente, para que, posteriormente, pudesse imitá-lo quando estivesse à frente de uma sala de aula, sem a preocupação com a crítica, reflexão ou criação. (GUEDES; SCHELBAUER, 2010).

Tanuri (2000) afirma que para romper com esse método mútuo, a formação dos professores passou a ser de responsabilidade das províncias, seguindo os padrões dos países europeus, com a instalação das escolas normais ${ }^{1}$ em todo o Brasil. Estas prosperaram por muitos anos, sendo fechadas e reabertas periodicamente, mas, colocando para a formação dos professores as mesmas disciplinas ofertadas nas escolas de primeiras letras, o que continuava desconsiderando o preparo didático-pedagógico, gerando inúmeras contestações e não havendo mudanças significativas para a formação dos professores. Assim,

[...] embora adotadas a partir de 1835, além de somente adquirir certa estabilidade após 1870 , permaneceram ao longo do século XIX como uma alternativa sujeita a contestações. Ilustra isso a posição de Couto Ferraz, que considerava as Escolas Normais muito onerosas, ineficientes qualitativamente e insignificantes quantitativamente, pois era muito pequeno o número de alunos formandos. (SAVIANI, 2009, p. 144).

Com o passar dos anos e das inúmeras críticas frente às Escolas Normais, surgiram novas instituições e novas formas de intervenções para formar professores, os chamados institutos de educação, implantados entre 1932 e 1933, tendo como foco não estava somente no ensino, mas também a pesquisa, que contribuiria para possíveis mudanças no paradigma vigente. (TANURI, 2000). Com isso,

[...] transformou as Escolas Normais em Escolas de Professores, cujo o currículo já incluía, já no primeiro ano, as seguintes disciplinas: 1) biologia educacional; 2) sociologia educacional; 3) psicologia educacional; 4) história da educação; 5) introdução

${ }^{1}$ Escolas normais, em que os professores eram formados apenas na observação, na qual não era necessária um estudo aprofundado sobre o assunto para se tornar um professor. 
ao ensino, contemplando três aspectos: a) princípios e técnicas; b) matérias de ensino abrangendo cálculo, leitura e linguagem, literatura infantil, estudos sociais e ciências naturais; c) prática de ensino, realizada mediante observação, experimentação e participação. Como suporte ao caráter prático do processo formativo, a escola de professores contava com uma estrutura de apoio que envolvia: jardim de infância, escola primária e escola secundária, que funcionavam como campo de experimentação, demonstração e prática de ensino. (SAVIANI, 2009, p. 145).

Por volta da metade da década de 1970, iniciam-se as críticas e rejeições a essa concepção técnica, movimento que foi alavancado com o fim da ditadura militar no Brasil e já, na década de 1980 “[...] a prática de professores deixa de ser considerada neutra e passa a constituir-se em uma prática educativa transformadora". (PEREIRA, 2000, p. 17).

Segundo Nóvoa (1992 apud NUNES, 2001), entre 1980 e 2000 as mudanças frente à formação dos professores começaram a ter relevância nos estudos científicos, novos métodos de ensino foram adotados para formar professores reflexivos e críticos no seu ponto de partida de se fazer a profissão docente, deixando para trás as concepções técnicas. Nesse contexto, os cursos superiores de licenciatura e até mesmo na educação básica, ganham um novo olhar com a promulgação da LDB 9.394/96 (BRASIL, 1996), que aponta,

[...] mudanças significativas em termos de caracterização e definições de critérios para a formação de professores e muitas discussões sobre seus encaminhamentos, ao se propor uma nova cara aos cursos de formação, pensando não mais na qualificação que estava centrada num conjunto de conhecimentos, habilidades e capacidades, mas ampliando esse contexto para além da formação humana e contemplando os problemas emergenciais como tecnologia, carga horária, infraestrutura, quantidade de prática, entre outros. (BENITES; SANTOS NETO; HUNGER, 2008, p. 351). 
Para Santos Neto (2002, p. 42) a educação vem sofrendo adequações, que para a sociedade atual são importantes, mas a educação escolar está em um momento de se repensar, pois o modo de se ensinar e a formação dos professores não são suficientes, porque "[...] existe um franco movimento no sentido de repensar a educação escolar - em meio a conflitos ideológicos em torno do que seja a educação escolar -, objetivando colocá-la em condições de responder aos desafios deste tempo".

Essa noção de ensino de Cursos de Formação de Professores nas áreas de licenciaturas é como um incentivo para o incremento de saberes para a atuação profissional, pois cabe às universidades apoiar os seus futuros docentes com uma formação diferenciada, na qual tenham vontade e condições para prosseguir nos seus estudos. (PEREIRA, 1999).

Assim, a formação profissional deve garantir meios que permitam ao docente adquirir capacidades de saber-analisar, saber-refletir e saber-justificar mediante suas ações práticas e experiências anteriores. (PERRENOUD et al., 2001). Logo, uma formação sólida e comprometida deve dar conta de partilhar um conhecimento teórico/prático significativo para que o docente seja capaz de atuar pedagogicamente no meio social e tenha condições de resolver as situações-problemas advindas dessa intervenção e de todo o universo escolar. (BORGES, 1998).

Quanto mais dinâmica e articulada for a formação, mais preparado o futuro professor estará, até porque:

Ninguém facilita o desenvolvimento daquilo que não teve oportunidade de aprimorar em si mesmo. Ninguém promove a aprendizagem de conteúdos que não domina, a constituição de significados que não compreende nem a autonomia que não pôde construir. É imprescindível que o professor que se prepara para lecionar na educação básica demonstre que desenvolveu ou tenha oportunidade de desenvolver, de modo sólido e pleno, as competências previstas para os egressos da educação básica. (MELLO, 2000, p. 103).

Segundo Moreira, Pereira e Lopes (2009) é necessário que o professor busque mais conhecimentos para adaptar os conteúdos vivencia- 
dos na formação inicial e domine o assunto que deseja abordar, pois a formação dos professores não atende todas as necessidades e precisa de uma formação continuada para contribuir no desenvolvimento dos seus alunos.

Desse modo, as reflexões sobre a formação profissional não terminam com a diplomação, é necessário que os profissionais estejam cientes que essa profissão, requer entendimento de que o profissional da educação será um eterno aprendiz. (PEREIRA, 2000).

O professor é um dos profissionais que mais necessidade tem de se manter atualizado, aliando à tarefa de ensinar a tarefa de estudar. Transformar essa necessidade em direito é fundamental para o alcance da sua valorização profissional e desempenho em patamares de competência exigidos pela sua própria função social. (MELO, 1999, p. 47).

Segundo Shigunov Neto e Maciel (2002), para que as mudanças na sociedade possam ser acompanhadas, precisa-se de novos professores do ensino, ou seja, profissionais que possam fazer a diferença no meio educacional, fomentando a reflexão crítica da prática pedagógica com atualizações nos conhecimentos curriculares frente às transformações sociais, mostrando que o professor deve se manter sempre atualizado e preocupado com a formação continuada, para que possa levar um ensino de qualidade aos educandos.

A Resolução CNE/CP n ${ }^{\circ}$ 1, de 18 de Fevereiro de 2002 (BRASIL, 2002), ainda em vigor no Brasil, e que orienta os cursos de licenciatura, não aponta exigências somente na formação de professores mais atualizados em tecnologias, mas também, na qualidade dos estágios e práticas de ensino, no que tange a aproximação com a realidade escolar, levando a [...] "reflexão na ação, experienciando cada instante do processo de educação como um novo instante, que, por si só, o é" (GONÇALVES JUNIOR; RAMOS, 1998, p. 3).

A essência da atividade (prática) do professor é o ensino-aprendizagem. Ou seja, é o conhecimento técnico prático de como garantir que a aprendiza- 
gem se realize em consequência da atividade de ensinar. Envolve, portanto, o conhecimento do objetivo, o estabelecimento de finalidades e a intervenção no objeto para que a realidade seja transformada enquanto realidade social. Isto é, a aprendizagem precisa ser compreendida enquanto determinada por uma realidade histórico-social. (PIMENTA, 1995, p. 61).

Espera-se que os estágios e práticas no processo de formação dos professores, possibilitem maior aproximação da realidade enfrentada pelos futuros professores, pois “"...] dessa forma, resgata a importância de se considerar o professor em sua própria formação, num processo de auto formação, de reelaboração dos saberes iniciais em confronto com sua prática vivenciada". (NUNES, 2001, p. 30).

Para Pimenta (1996), o conhecer a partir de visitas e estudos sobre a realidade escolar serve para preparar melhor os futuros docentes, fazendo desse espaço o meio de aprendizado para sua futura atuação, já que vivenciar situações em que o conhecimento pode ser aplicado é extremamente válido ao graduando.

Therrien (1995 apud NUNES, 2001) salienta que os estudos sobre a formação de professores ainda persistem numa separação entre a teoria e a prática na educação, não abordando questões dos saberes que são aprendidos na prática.

De certa forma, o repensar a concepção da formação dos professores, que até a pouco tempo objetivava a capacitação destes, através da transmissão do conhecimento, a fim de que "aprendessem" a atuar eficazmente na sala de aula, vem sendo substituído pela abordagem de analisar a prática que este professor vem desenvolvendo, enfatizando a temática do saber docente e a busca de uma base de conhecimento para os professores, considerando os saberes da experiência. (NUNES, 2001, p. 38).

Logo, a articulação teoria e prática contribuirá na formação dos professores de forma contínua e coletiva, utilizando a prática pedagógica 
como forma de problematização, significação e exploração dos conteúdos da formação teórica. (NUNES, 2001).

Isto posto, surgiu a seguinte indagação como os alunos formandos (penúltimo e último semestre) de cursos de licenciatura percebem a preparação para sua atuação futura como professores de educação básica?

Dessa forma, o objetivo do presente estudo foi identificar a percepção dos alunos do penúltimo e último semestre de cursos de licenciatura, em relação a preparação para a atuação docente futura na educação básica.

\section{METODOLOGIA}

Esta pesquisa caracteriza-se como descritiva, uma vez que teve “[...] como objetivo primordial a descrição das características de determinada população [...]" (GIL, 2008, p. 27) e de abordagem qualitativa, pois buscou a "[...] compreensão detalhada dos significados e características situacionais apresentadas". (RICHARDSON, 1999, p. 90).

A pesquisa foi realizada em uma Instituição de Ensino Superior (IES) localizada na região metropolitana de Cuiabá-MT, selecionada pelo critério de acessibilidade proposto por Gil (2008). Os participantes da pesquisa constituíram-se por alunos formandos do penúltimo e último semestre dos cursos de licenciatura desta IES. Assim, nesse momento, a amostra foi não probabilística, visto que baseou-se, “[...] em procedimentos subjetivos, qualitativos e [é] [foi] escolhida por acessibilidade [...]". (BRASILEIRO, 2013, p. 52).

Participaram da pesquisa 34 alunos do curso de Educação Física, sendo 21 homens e 13 mulheres e, destes 21 cursavam o último semestre e 13 o penúltimo semestre; 10 alunas do curso de Pedagogia, 8 cursavam o penúltimo semestre e 2 o último semestre e 5 alunos do curso de Letras, sendo 4 mulheres e 1 homem, 4 cursavam o último semestre e somente 1 o penúltimo semestre. A idade média dos sujeitos da pesquisa é 30 anos.

Utilizamos como instrumento de coleta de dados um questionário direcionado aos alunos dos cursos de licenciatura, constituído por 03 questões abertas e 15 fechadas, com justificativas, abordando informações por levantamento de perfil (nome, idade, sexo e curso) e percepção dos alunos sobre experiências durante a graduação. 
Durante a coleta dos dados contatamos os coordenadores dos cursos de licenciatura da IES para explicarmos os objetivos da pesquisa e, agendamos um horário para conversar com os alunos, buscando não interromper as atividades cotidianas.

Nos dias previamente marcados, fomos nas salas de aula, explicamos aos alunos os objetivos e metodologia da pesquisa e entregamos três vias, sendo uma com o questionário aplicado e outras duas com o Termo de Consentimento Livre e Esclarecido (TCLE) autorizando a utilização dos dados coletados, ficando uma dessas vias com o acadêmico participante (assinado).

A análise de dados ocorreu a partir da categorização das respostas:

As propostas fornecidas pelos elementos pesquisados tendem a ser as mais variadas. Para que essas respostas possam ser adequadamente analisadas, torna-se necessários, portanto, organizá-las, o que é feito mediante o seu agrupamento em certo número de categorias. (GIL, 2008, p. 157).

De acordo com o autor, esse processo de definição de categorias deve considerar dois princípios importantes: o número de categorias criadas deve ser suficiente para incluir todas as respostas identificadas e uma mesma resposta não pode ser classificada em mais de uma categoria. Caso isso ocorra, o processo de categorização deve ser revisto.

Ressaltamos que esta pesquisa foi autorizada pelo Comitê de Ética do Centro Universitário de Várzea Grande - UNIVAG, parecer número $1.466 .371 / 2016$.

\section{APRESENTAÇÃO E ANÁLISE DOS DADOS}

Os dados serão apresentados e discutidos questão a questão, de modo a atingir o objetivo deste estudo que foi identificar a percepção dos alunos do penúltimo e último semestre de cursos de licenciatura, em relação à preparação para a atuação docente futura na educação básica. Lembramos que este estudo não tem por objetivo a comparação dos resultados, mas apresentar um panorama geral sobre a preparação dos alunos 
nos cursos de licenciatura na referida IES.

Na questão 1, perguntamos aos alunos sobre o porquê da escolha do respectivo curso. Por ser uma questão aberta, ao aproximarmos as respostas, identificamos 5 categorias, apresentadas a seguir.

Tabela 1: Justificativas dos alunos por escolher cursos de licenciatura (Educação Física, Pedagogia e Letras).

MANIFESTAÇÃO DOS ALUNOS

FREQUÊNCIA

Perceberam afinidade com o curso em questão, desde o Ensino Médio

Já tiveram experiências anteriores com o esporte

15

11

Entendem que o mercado de trabalho na área escolhida é promissor

08

Tem familiares que trabalham na área

04

Ajuda na melhoria da qualidade de vida (saúde)

Nota: construção dos autores

Identificamos três categorias gerais, ou seja, presentes nas respostas dos alunos dos três cursos (Educação física, Letras e Pedagogia) e duas categorias específicas aos alunos do curso de licenciatura em Educação Física.

Entre as categorias gerais, $36 \%$ dos alunos responderam que escolheram o curso por perceberam afinidade com o mesmo desde o Ensino Médio. Outros 9\% dos alunos apontaram que foi por incentivo da família, uma vez que esses já atuavam na área em questão, indo ao encontro com as ideias de Machio et al. (2009, p. 5), que afirmam que: [...] "parte significativa de alunos escolheram o curso por opção, tendo claro e definido o gosto pela profissão professor". Além disso, 19\% dos alunos vincularam a opção da profissão futura a possibilidade de inserção no mercado de trabalho.

Especificamente, em relação ao curso de Educação Física, 73\% do total de alunos do respectivo curso, participantes desta pesquisa, justificaram a escolha por motivo das experiências anteriores com o esporte e $27 \%$ pelo curso ser propício a maior qualidade de vida. Segundo Santini e Molina Neto (2005) muitos alunos do curso de Educação Física são 
ex-atletas ou pessoas que já tiveram contato com a área esportiva e que, quando precisa fazer escolha de uma profissão, escolhem aquele que eles têm mais familiaridade.

Importante ressaltar três sujeitos (todos do curso de Letras) responderam não saber o porquê da escolha do referido curso. Para nós, esse dado preocupa, especialmente porque, de acordo com Santini e Molina Neto (2005) a escolha da profissão, quando não é feita com consciência, pode trazer frustração futura, levando o aluno a um descontentamento com a profissão.

Na questão 2 perguntamos se os alunos perceberam a articulação entre os conteúdos ministrados na graduação em relação ao campo de atuação profissional. Por ser uma questão fechada, havia três opções para resposta: sempre, às vezes e nunca, sendo que a opção nunca não foi assinalada.

Figura 1: Articulação entre os conteúdos ministrados na graduação e campo de atuação

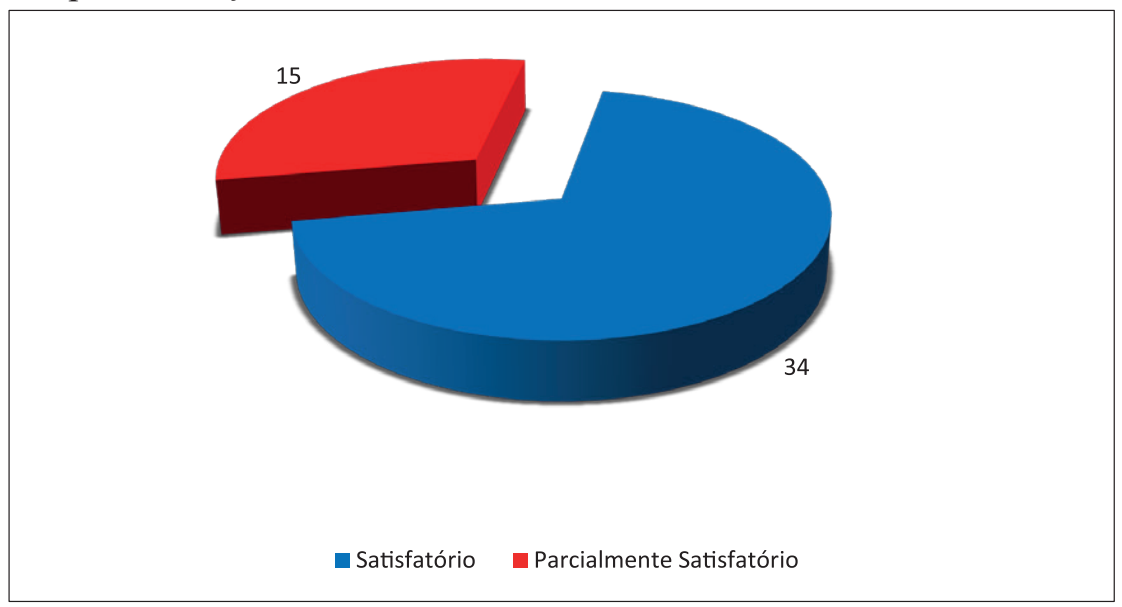

Nota: construção dos autores

Notamos que 69\% (34 alunos) dos alunos perceberam articulação entre os conteúdos ministrados na graduação em relação ao campo de atuação do professor e $31 \%$ (15 alunos) apenas às vezes perceberam tal articulação. 
Por um lado, o resultado encontrado é satisfatório, na medida em que nenhum aluno assinalou nunca e mais da metade dos sujeitos assinalaram sempre. No entanto, ainda existem alunos com dificuldades em perceber tal articulação, uma vez que $31 \%$ responderam, às vezes, o que serve de alerta.

Na questão 3 perguntamos se os alunos, durante a formação, tiveram a oportunidade de refletir sobre a organização da educação básica, nos diferentes níveis de ensino, havendo três opções para resposta: sempre, às vezes e nunca, sendo que nenhum aluno assinalou a opção nunca.

Figura 2: Oportunidade de refletir sobre os diferentes níveis de ensino

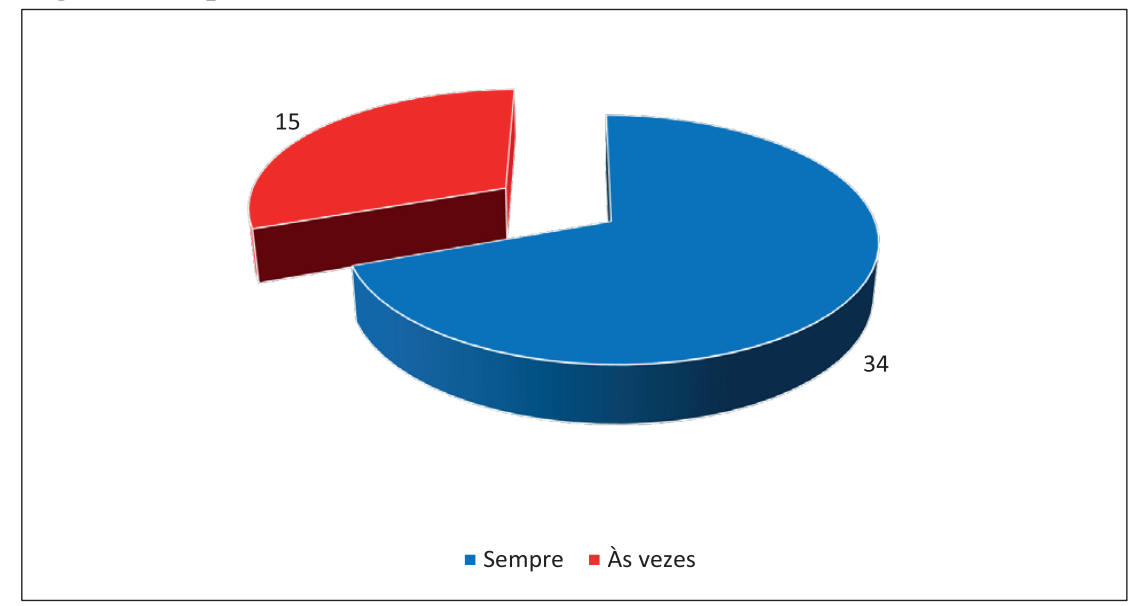

Nota: construção dos autores

Na figura 2, notamos que $69 \%$ dos alunos (34) tiveram oportunidade de refletir sobre a organização da educação básica, nos diferentes níveis de ensino e $31 \%$ (15) às vezes tiveram tal oportunidade.

Ainda que os quantitativos sejam idênticos à questão 2, as análises não foram realizadas conjuntamente, pois os sujeitos não tiveram as mesmas respostas nas questões. Assim, trata-se apenas de uma coincidência.

Por outro lado, o argumento supracitado na questão 2 nos ajudou a analisar a questão 3 , tanto por nenhum sujeito ter assinalado a questão nunca, como pelo alerta necessário a 31\% responderem parcialmente, es- 
pecialmente porque refletir sobre a organização da educação básica nos diferentes níveis de ensino, é de fundamental importância, pois permite ao futuro professor conhecer as peculiaridades de cada uma das diferentes etapas do desenvolvimento humano.

Na questão 4 questionamos se os alunos tiveram vivências com alunos da educação básica na própria escola, havendo as opções de resposta: sempre, raramente e nunca.

Figura 3: Vivências com alunos da educação básica na própria escola

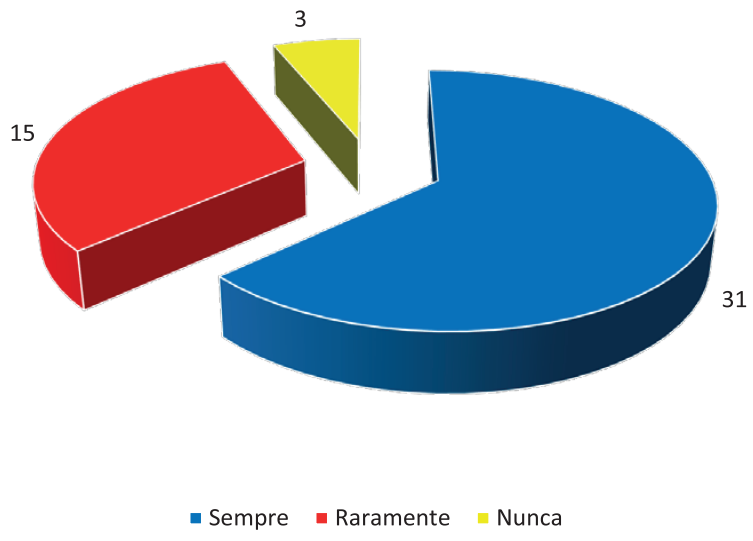

Nota: construção dos autores

Identificamos que $63 \%$ dos alunos (31) tiveram vivências com alunos da educação básica na própria escola, 31\% (15) raramente e 6\% (3) nunca tiveram².

Ao somarmos as respostas de raramente e nunca (37\%), surgiu uma preocupação, pois entendemos que vivências com alunos da educação básica contribuem demasiadamente na formação do futuro professor, facilitando sua futura atuação docente. Tal ausência, pode gerar insegurança na atuação docente futura. Além disso, Pimenta (1996) reforça que quanto mais visitas e vivências práticas o aluno tiver em sua graduação

\footnotetext{
${ }^{2} \mathrm{O}$ percentual referente a opção nunca corresponde a resposta dos alunos do curso de letras do último semestre de letras, ampliando nossa preocupação. No entanto, consideramos também que esses alunos sequer consideraram as oportunidades dos estágios, que ocorrem em todos os cursos pesquisados.
} 
mais preparado ele estará para a realidade escolar.

Na questão 5 perguntamos se os alunos estudaram o desenvolvimento e crescimento de crianças e adolescentes durante a graduação e, caso a resposta fosse positiva, se isso ocorreu de maneira satisfatória ou não. Do total de sujeitos, 01 respondeu que não estudou sobre esse tema (acadêmico do curso de Letras do penúltimo semestre). Dos 48 alunos que responderam terem estudado, nenhum aluno assinalou a opção não.

Figura 4: Conhecimentos sobre crescimento e desenvolvimento de crianças e adolescentes

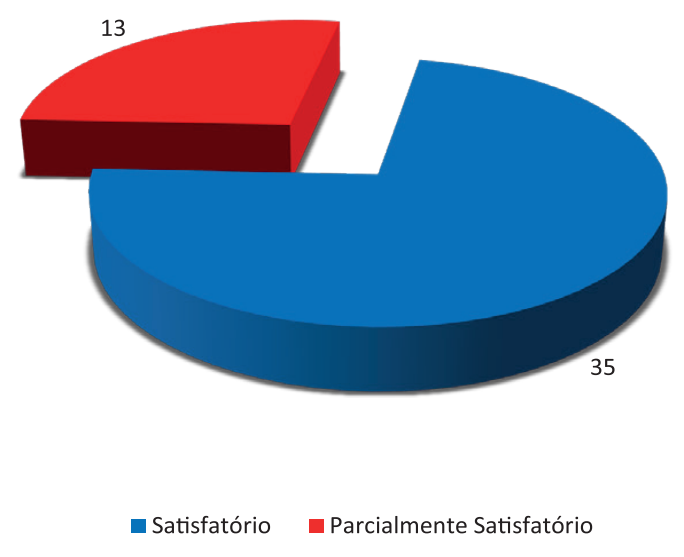

Nota: construção dos autores

Identificamos que $73 \%$ dos alunos (35) responderam que foi satisfatório o estudo sobre o desenvolvimento e crescimento de crianças e adolescente e $27 \%$ (13) responderam que isso ocorreu de maneira parcialmente satisfatória.

Entendemos que esse resultado é positivo, pois o professor deve conhecer seu aluno para melhor ensinar, mesmo porque, segundo Gallahue e Ozmun (2005, p. 3): “[...] sem um profundo conhecimento dos aspectos do desenvolvimento do comportamento humano, os educadores somente podem supor as técnicas educacionais e os procedimentos de intervenção apropriados".

Além disso, Brasil (2002, p. 3) determina em seu parágrafo $6^{\circ}$ 
que:

$\S 3^{\circ} \mathrm{A}$ definição dos conhecimentos exigidos para a constituição de competências deverá, além da formação específica relacionada às diferentes etapas da educação básica, propiciar a inserção no debate contemporâneo mais amplo, envolvendo questões culturais, sociais, econômicas e o conhecimento sobre o desenvolvimento humano e a própria docência $[\ldots]$

Na questão 6, unanimemente, os alunos responderam que estudaram sobre como planejar uma aula. Nessa questão, perguntamos ainda sobre a qualidade dessa formação, havendo três opções para resposta satisfatório, parcialmente satisfatório e não satisfatório, sendo que nenhum aluno assinalou essa última opção.

Figura 5: Satisfação em relação as discussões sobre como planejar aulas

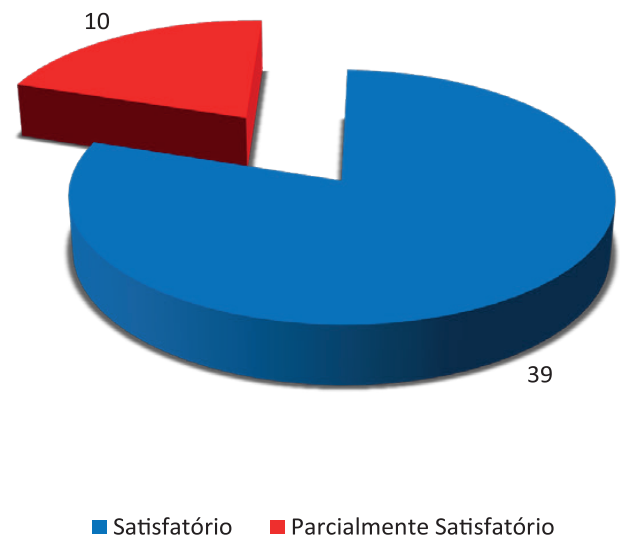

Nota: construção dos autores

Verificamos que $80 \%$ dos alunos (39) disseram que os estudos sobre elaboração de planos de aula foram satisfatórios e 20\% (10) de maneira parcialmente satisfatória, sendo que os alunos que assinalaram esta opção eram de cursos diferentes (Educação física, Letras e Pedagogia). 
Os dados supracitados mostram pontos positivos pelo alto percentual de alunos que disseram estarem satisfeitos com as discussões sobre como elaborar planos de aula, potencializando a organização das aulas e diminuição dos improvisos e aulas repetitivas. (LIBÂNNEO, 1994).

Perguntarmos ainda na questão 7 se tiveram a oportunidade de elaborar planos de aula para diferentes idades, havendo três opções para resposta: sempre, às vezes e nunca.

Figura 6: Oportunidade de planejar aulas para diferentes idades

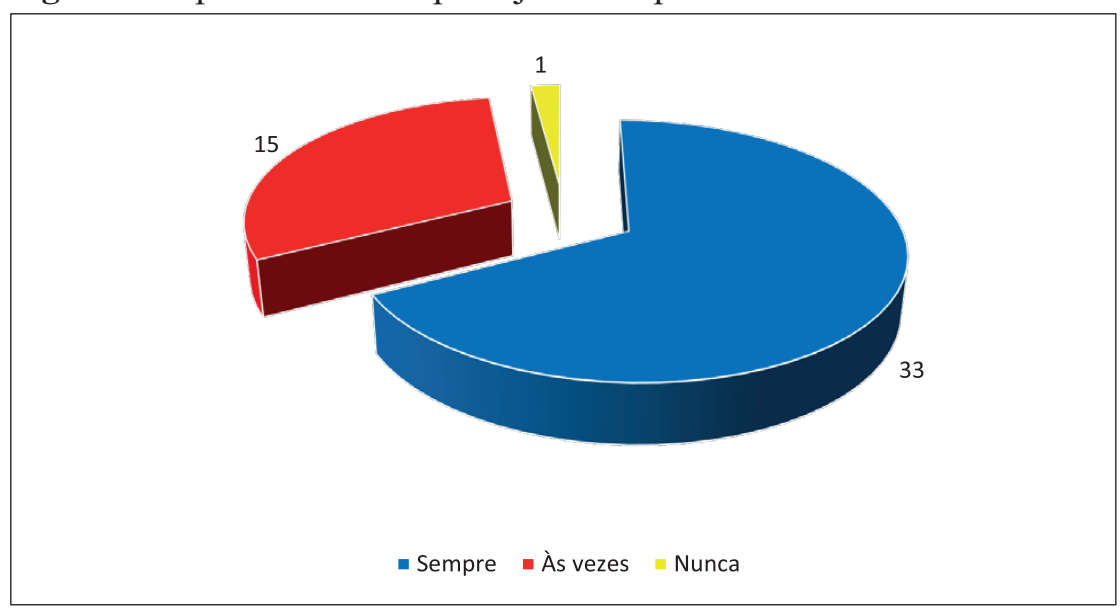

Nota: construção dos autores

Observamos que $67 \%$ dos alunos (33) tiveram oportunidade de elaborar planos de aula para diferentes idades, $31 \%$ (15) às vezes e 2\% (1) nunca tiveram essa experiência.

Mais do que saber elaborar, é fundamental vivenciar e aplicar tais conhecimentos, mesmo porque Brasil (2002) determina que a prática deve acompanhar a formação desde o primeiro semestre do curso. Assim, no curso de educação física encontramos seis alunos que assinalaram às vezes, já no curso de pedagogia foram sete alunos e no curso de letras três, às vezes, e um nunca. Com isso, os cursos precisam rever os casos dos alunos que assinalaram nunca e às vezes, não apenas para atender a diretriz curricular estabelecida como documento orientador dos projetos pedagógicos de cursos, mas, principalmente, pensando na contribuição 
e qualidade da formação desse futuro professor. Precisamos considerar ainda se os alunos que responderam nunca e às vezes consideraram os estágios, pois esses, ainda que não sejam os únicos, não deixam de ser momentos em que o aluno está na prática.

$\mathrm{Na}$ intenção de completar as questões 6 e 7, na questão 8 perguntamos aos alunos se tiveram a oportunidade de elaborar planos de aula e aplicá-los para diferentes idades, disponibilizamos 3 opções para resposta: sempre, às vezes e nunca, sendo que nenhum aluno assinalou a questão nunca.

Com isso, identificamos divergências nas respostas dos sujeitos, pois na questão anterior um aluno apontou que nunca teve a oportunidade de elaborar planos de aula para diferentes idades, mas na questão 8 nenhum aluno apontou tal opção.

Figura 7: Oportunidade para planejar aulas e aplicá-los para diferentes idades

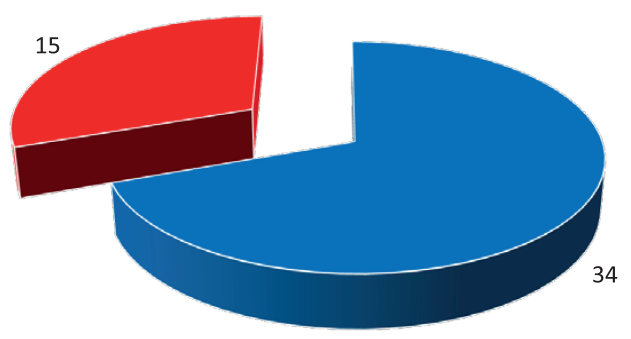

- Sempre às vezes

Nota: construção dos autores

Verificamos que $69 \%$ dos alunos (34) sempre tiveram oportunidade de elaborar planos de aula e aplicá-los para diferentes idades e 31\% (15) às vezes.

Se por um lado é positivo que quase $70 \%$ dos alunos tenham elaborado e aplicado planos de aula, precisamos ainda nos preocupar com 
os alunos que apenas às vezes tiveram tal experiência, especialmente, porque de acordo com Brasil $(2002$, p. 3) " [...] a simetria invertida, onde o preparo do professor, por ocorrer em lugar similar àquele em que vai atuar, demanda consistência entre o que faz na formação e o que dele se espera;"

Para complementar as questões anteriores quanto às experiências com o planejamento, na questão 9 perguntamos se estudaram sobre como elaborar um plano de ensino, sendo que 4 alegaram que nunca tiveram essa experiência, sendo três alunos do curso de Educação Física e um aluno do curso de Letras.

Entre os 45 alunos que tiveram essa vivência, perguntamos ainda sobre a qualidade dessa formação, havendo três opções para resposta satisfatório, parcialmente satisfatório e não satisfatório, sendo que nenhum aluno assinalou a opção não.

Figura 8: Estudo sobre como planejar aulas

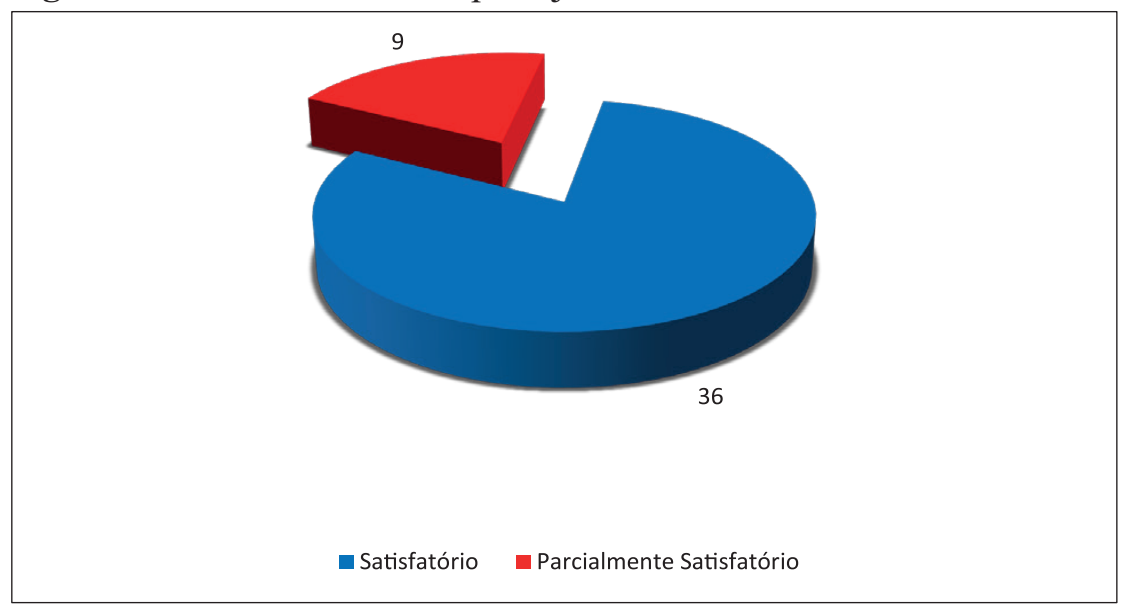

Nota: construção dos autores

Observamos que $80 \%$ dos alunos (36) responderam que foi de maneira satisfatória o estudo sobre como elaborar um plano de ensino e 20\% (9) de maneira parcialmente satisfatória.

Planejar é essencial a toda ação humana, se houver intenção de êxito na ação, especialmente porque corresponde a "um processo de ra- 
cionalização, organização e coordenação da ação docente, articulando a atividade escolar e a problemática do contexto social". (LIBÂNEO, 1994, p. 222). Portanto, esperávamos que $100 \%$ dos alunos tivessem acesso a essas informações/ experiências.

No entanto, observamos que os mesmos alunos que entendem que os estudos sobre elaboração/aplicação de aula ocorreram de forma parcialmente satisfatória, replicaram as respostas sobre o plano de ensino, ampliando a necessidade de ou revisar a proposta pedagógica e planos de ensino dos cursos pesquisados, ou mesmo que os professores em sala de aula reforcem os momentos das práticas ou estágios para que os alunos as percebam com maior facilidade.

Ao perguntarmos na questão $\mathbf{1 0}$ se estudaram diferentes metodologias para o ensino à crianças e adolescentes, disponibilizamos três opções para resposta: sempre, às vezes e nunca.

Figura 9: Estudo de diferentes metodologias para o ensino a crianças e adolescentes

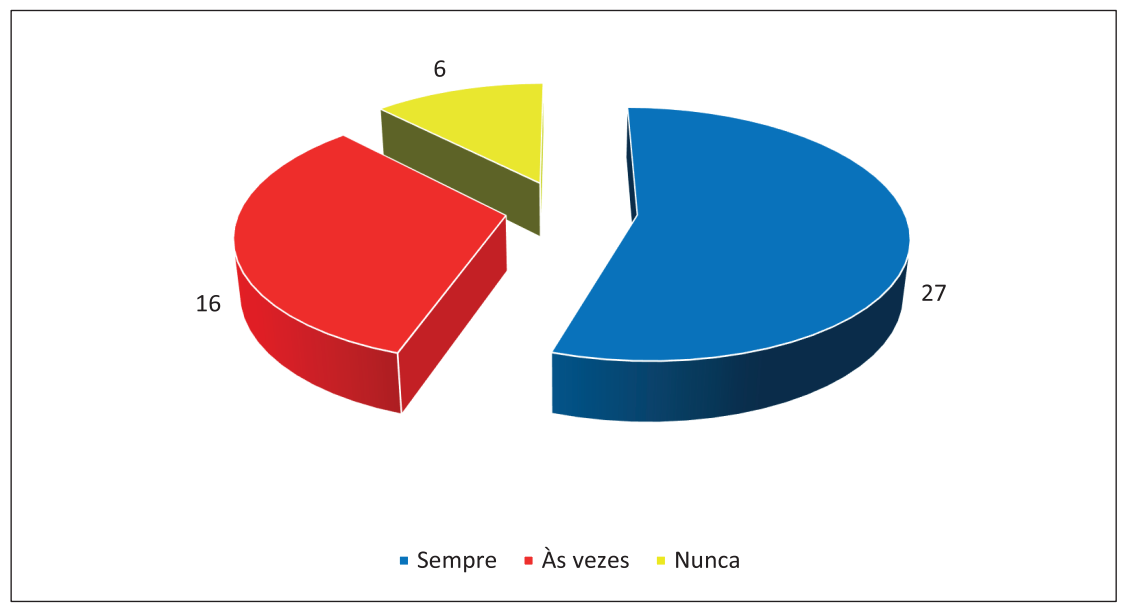

Nota: construção dos autores

Verificamos que 55\% dos alunos (27) estudaram diferentes metodologias para o ensino à crianças e adolescente, $33 \%$ (16) às vezes estudaram e $12 \%$ (6) nunca. Vale destacar que estes $12 \%$ referem-se a respos- 
ta de três alunos de letras e três alunos de pedagogia.

As estratégias "[...] referem-se aos meios para alcançar objetivos [...] do ensino, ou seja, ao "como" do processo de ensino, englobando as ações a serem realizadas pelo professor e pelos alunos para atingir os objetivos e conteúdos." (LIBÂNEO, 1994, p. 149, grifos do autor).

Com isso, é necessário que os futuros docentes compreendam os diferentes métodos de ensino para que possam saber como organizar seus trabalhos pedagógicos, para que suas ações atinjam seus objetivos.

Assim, é preocupante o percentual que teremos se somarmos os alunos que responderam nunca e às vezes, $45 \%$, que demonstra um percentual alto dos alunos que responderam, servindo de alerta aos cursos pesquisados.

$\mathrm{Na}$ intenção de levantar mais informações com os sujeitos participantes, na questão 11 perguntamos aos alunos se gostariam de registrar algo sobre a formação que receberam, pensando na preparação para a futura intervenção docente na educação básica, mas não tivemos nenhuma resposta.

Das questões 12 a 17 apresentamos algumas situações hipotéticas que poderiam ocorrer se o aluno fosse contratado naquele momento para atuar como docente em uma escola, pensando em possíveis dificuldades.

Para facilitar a visualização das respostas, optamos por agrupar as situações e as respectivas respostas, sim ou não, em uma tabela, apresentada a seguir:

Tabela 2: Se você fosse contratado hoje para dar aula em uma escola

SITUAÇÕES-HIPOTÉTICAS APRESENTADAS $\quad$ SIM NÃO

Teria dificuldades em tudo, pois a graduação teve inúmeras falhas

Teria dificuldade na falta de infraestrutura e materiais adequados

Teria dificuldade para planejar, mas não para aplicar aulas

12

Teria dificuldade para aplicar, mas não para planejar a aula

Teria dificuldade para se relacionar com os alunos

Teria dificuldade para explicar sobre a relevância da sua disciplina

Nota: construção dos autores 
De maneira geral, teríamos a seguinte situação: em média, $82 \%$ dos sujeitos da pesquisa (43) não teriam dificuldades, entre as apresentadas, o que consideramos como fator positivo, indicando, como propõem Perrenoud et al. (2001) que a formação acadêmica deve garantir ao futuro docente uma preparação profissional de qualidade, na qual os conhecimentos pedagógicos atendam a realidade da educação básica.

Identificamos coerência ao analisarmos possíveis dificuldades com o planejamento/ aplicação das aulas, em relação as perguntas anteriores presentes no instrumento desta pesquisa, fator positivo ao nosso entendimento.

Entendemos como dado positivo também os sujeitos não verem dificuldades com a relação futura com seus alunos, 98\% (48), especialmente porque segundo Haidt (1994), as relações professor/aluno são de fundamental importância para o desenvolvimento de hábitos e atitudes para o convívio social, como cooperação e respeito. É dessa forma que o futuro docente ganhará confiança/respeito dos alunos.

Justificar a relevância da disciplina que ministra é obrigação do docente, elucidando o que, como e por que fazer, significando que o professor tem que saber a importância da sua disciplina para a vida dos alunos e sociedade, uma vez que, todos os membros da comunidade escolar entendam que a [...] "prática educativa é um fenômeno social e universal, sendo uma atividade humana necessária à existência e funcionamento de todas as sociedades". (LIBÂNEO, 1994, p. 16). Assim, ainda que 80\% dos sujeitos (39) apontaram que não terão dificuldades para tal justificativa, preocupa-nos aqueles que terão.

Por fim, deixamos em aberto a questão 18 para os alunos acrescentarem opiniões sobre as dificuldades relacionadas à sua formação/ preparação docente futura. Apenas quatro alunos apontaram, sendo:

"O que aprendi na teoria e prática está sendo suficiente para eu reger aulas com crianças de diversas idades". (SUJEITO 1).

"A graduação foi interessante, mas é sempre bom o professor buscar mais". (SUJEITO 2).

"Cabe ao professor inovar nas suas aulas mesmo havendo dificuldade, com materiais e infraestruturas". (SUJEITO 3). 
"Dificuldade em trabalhar na Educação Infantil mesmo sendo uma faixa etária maravilhosa". (SUJEITO 4).

A resposta do SUJEITO 1 demostra que este está satisfeito com a sua formação acadêmica, o que indica, segundo Libâneo (1994), que conseguiu compreender os conhecimentos curriculares teóricos e práticos que, em articulação, deu suporte e segurança ao mesmo para poder atuar futuramente nos diferentes níveis de ensino na Educação Básica. Diante disso, identificamos uma relação com a opinião do SUJEITO 2, que afirmou que a formação não termina com a diplomação, mas reconhece a necessidade do professor buscar novos conhecimentos. Assim, mesmo com a satisfação do SUJEITO 1 é necessário sempre um estudo contínuo.

O SUJEITO 3, entende que é importante o professor sempre inovar em suas práticas pedagógicas, para que o futuro docente consiga encontrar estratégias para solucionar problemas na realidade escolar, principalmente na falta de infraestrutura e materiais, que segundo Pereira (2010, p. 6) [...] "a carência de materiais restringe as oportunidades para variação das atividades" [...], o que desmotiva o professor na prática pedagógica, mesmo estando preparado para a atuação.

Na resposta do SUJEITO 4, identificamos dificuldades em atuar com a Educação Infantil, servindo de alerta para a ampliação dessas vivências durante a formação.

\section{CONCLUSÃO}

Ao refletirmos sobre os "achados" desta pesquisa, entendemos que, mesmo com a dificuldade encontrada durante todo o trajeto do estudo, que foi o número reduzido de alunos, o ir e vir à IES para conseguir finalizar a coleta de dados, os objetivos foram atingidos.

Destacando os principais resultados, identificamos que $36 \%$ dos sujeitos escolheram o curso por perceberem afinidades com o Ensino Médio, reforçando a importância desse nível de ensino, e das informações ali abordadas na formação dos alunos.

Os alunos alegaram ainda que não terão dificuldades em se relacionar com os alunos na Educação Básica (98\%). Entendemos que os estágios e atividades práticas em muito contribuem com essa formação. 
Verificamos que $82 \%$ dos sujeitos alegam que a graduação não apresentou dificuldades, sendo um indicador de que os conhecimentos ministrados na IES são oferecidos de maneira satisfatória. Em contrapartida, verificamos que $31 \%$ dos sujeitos alegam estarem pouco satisfeitos com os conhecimentos adquiridos, visto que os conteúdos não apresentam articulação entre graduação e atuação futura do professor.

Destacamos ainda que, $80 \%$ dos alunos entendem que estão preparados para expor a relevância da sua disciplina na escola, capacidade fundamental que permitirá aos futuros alunos da Educação Básica não questionarem essas aulas.

Ainda, 80\% dos sujeitos pesquisados aprenderam como planejar suas aulas, fator imprescindível na vida profissional do professor, uma vez que, sem o planejamento o professor não consegue adotar um caminho certo e contínuo rumo ao processo de ensino e aprendizagem dos alunos da Educação Básica. No entanto, identificamos ainda que, existem alunos que não aprenderam planejar, fato preocupante, pois, esperávamos um resultado de $100 \%$ frente a relevância da ação de planejar na futura atuação docente, levando a IES e os professores dos respectivos cursos a repensarem as propostas pedagógicas para melhor atender as necessidades dos alunos em compreenderem o plano de ensino.

Entre as situações apresentadas neste estudo, $82 \%$ dos alunos entendem que não teriam dificuldades. No entanto, a falta de infraestrutura e materiais adequados, gera insegurança em quase $50 \%$ dos alunos.

Concluímos que os sujeitos desta pesquisa, de maneira geral, identificam a contribuição do ensino superior em sua preparação para a atuação como docente, indicando que a instituição pesquisada caminha em uma direção de formação de qualidade desses futuros professores.

\section{REFERÊNCIAS}

BENITES, Larissa Cerignoni; SANTOS NETO, Samuel de Souza; HUNGER, Dagmar. O processo de constituição histórica das diretrizes curriculares na formação de professores de educação física. São Paulo: Educação e pesquisa, v. 34, n. 2, p. 343-360, maio/ago. 2008.

BRASIL. Lei n ${ }^{\circ}$ 9.394, de 20 de dezembro de 1996. Estabelece as Diretrizes e Bases da Educação Nacional. Diário Oficial [da] 
República Federativa do Brasil, Poder Executivo, Brasília, DF, 23 dez. 1996. Seção I, p. 27833-27841.

BRASIL. Resolução CNE/CP 1, de 18 de fevereiro de 2002. Institui Diretrizes Curriculares Nacionais para a Formação de Professores da Educação Básica, em nível superior, curso de licenciatura, de graduação plena. Diário Oficial [da] República Federativa do Brasil, Poder Executivo, Brasília, DF, 4 mar. 2002. Seção I, p. 8-9.

BRASILEIRO, Ada Magaly Matias. Dimensão metodológica do texto científico. In: BRASILEIRO, Ada Magaly Matias. Manual de produção de texto acadêmico e científico. São Paulo: Atlas, 2013.

BORGES, Cecília Maria Ferreira. O professor de educação física e a construção do saber. Campinas: Papirus, 1998.

GALLAHUE, David L.; OZMUN, John C. Compreendendo o desenvolvimento motor: bebês, crianças, adolescentes e adultos. 3 ed. São Paulo: Phorte, 2005.

GIL, Antônio Carlos. Métodos e técnicas de pesquisa social. 6. ed. São Paulo: Atlas, 2008.

GONÇALVES JUNIOR, Luiz; RAMOS, Glauco N. S. A prática de ensino e o estágio supervisionado nos cursos de licenciatura em educação física. São Paulo: Revista da Unicastelo, v. 1, n. 1, p. 1-5, 1998.

GUEDES, Shirlei Terezinha Roman; SCHELBAUER, Analete Regina. Da prática do ensino à prática de ensino: os sentidos da prática na formação de professores no Brasil do século XIX. Revista Histedbr, p. 227-245, maio/jun. 2010.

HAIDT, Regina Celia Cazaux. Curso de didática geral. São Paulo: Ática, 1994.

LIBÂNEO, José Carlos. Didática. São Paulo: Cortez, 1994. 
MEDEIROS, Amanda Ssantos. Influências dos aspectos físicos e didáticos pedagógicos nas aulas de educação física em escolas municipais de Belém. Revista Científica da UFPA, v. 7, n. 1, 2009.

MELLO, Guiomar Namo de. Formação inicial de professores para a educação básica: uma (re) visão radical. Revista São Paulo em Perspectiva, v. 14, n. 1, 2000, p. 98-110.

MOREIRA, Evando Carlos; PEREIRA, Raquel Stoilov; LOPES, Tomires Campos. Consolidando caminhos e caminhadas da educação física nas séries finais do ensino fundamental. In: MOREIRA Evando Carlos; NISTA-PICCOLO, Vilma Leni (orgs.). O quê e como ensinar educação física na escola, Jundiaí: Fontoura, 2009.

NUNES, Célia Maria Fenrnades. Saberes docente e formação de professores: um breve panorama da pesquisa Brasileira. Educação \& Sociedade, v. 22, n. 74, p. 27- 42, abr. 2001.

PEREIRA, Júlio Emílio Diniz. Debates e pesquisas no Brasil sobre formação docente. In: PEREIRA, Júlio Emílio Diniz. Formação de professores: pesquisas, representações e poder. Belo Horizonte: Autêntica, 2000.

PEREIRA, Júlio Emílio Diniz. As mudanças na educação básica e a formação docente. Educação \& Sociedade, a. 20, n. 68, p. 115-117, dez. 1999.

PEREIRA, Luciana Padilha. O exercício da docência e as dificuldades da prática pedagógica: o caso da educação física. 2010. Trabalho de Conclusão de Curso (Licenciatura Plena em Educação Física) UNIVAG, Centro Universitário de Várzea Grande, Várzea Grande, MT, 2010.

PERRENOUD, Philippe. (org.). Formando professores profissionais: quais as estratégias? quais as competências? 2. ed. Porto Alegre: Artmed, 2001.

PIMENTA, Selma Garrido. Formação de professores: saberes da 
docência e identidade do professor. São Paulo: Revista faculdade de educação, v. 22, n. 2, p.72-89, jul./dez. 1996.

PIMENTA, Selma Garrido. O estágio na formação de professores: unidade entre teoria e prática? Caderno de pesquisa, São Paulo, n. 94, p. 58-73, ago./set. 1995.

RICHARDSON, Roberto Jarry et al. Pesquisa social: métodos e técnicas. São Paulo: Atlas, 1999.

SANTOS NETO, Elydio. Aspectos humanos da competência docente: problemas e desafios para formação de professores. In: SEVERO, Antonio Joaquim; FAZENDA, Ivani Catarina Arantes (orgs.).

Formação docente rupturas e possibilidades. Campinas: Papirus, 2002.

SANTINI, Joarez; MOLINA NETO, Vicente. A síndrome do esgotamento profissional em professores de Educação Física: um estudo na rede municipal de ensino de Porto Alegre. Revista Brasileira de Educação Física e Esporte, São Paulo, v. 19, n. 3, p. 209-222, jul./set., 2005.

SAVIANI, Demerval. Formação de professores: aspectos históricos e teóricos do problema no contexto brasileiro. Revista brasileira de educação, v. 14, n. 40, p. 143-155, jan./abr. 2009.

SHIGUNOV NETO, Alexandre; MACIEL, Lizete Shizue Bomura (orgs.). Reflexões sobre a formação de professores. Campinas: Papirus, 2002.

TANURI, Leonor Maria. História da formação de professores. Revista Brasileira de Educação, n. 14, p. 61-88, maio/ago. 2000.

TANURI, Leonor Maria. O estágio na formação de professores: unidade entre teoria e prática? Caderno de Pesquisa, São Paulo, n. 94, p. 58-73, ago./set. 1995.

Recebido em: 25/06/19

Aprovado em: 10/03/20 